\title{
Experimental Investigation of SAHs Solar Dryers with Zigzag Aluminum Cans
}

\author{
Mustafa Adil, Osama Ibrahim, Zainalabdeen Hussein, Kaleid Waleed
}

Renewable Energy Research Center, University of Anbar, Ramadi, Iraq

Email address:

mnmaab@leeds.ac.uk (M. Adil), osama_eng21@yahoo.com (O. Ibrahim), zeen_huss2002@yahoo.com (Z. Hussein), kaleidwaleed@yahoo.com (K. Waleed)

\section{To cite this article:}

Mustafa Adil, Osama Ibrahim, Zainalabdeen Hussein, Kaleid Waleed. Experimental Investigation of SAHs Solar Dryers with Zigzag Aluminum Cans. International Journal of Energy and Power Engineering. Vol. 4, No. 5, 2015, pp. 240-247. doi: 10.11648/j.ijepe.20150405.11

\begin{abstract}
This experimental study investigates the thermal performance of two different solar-air collector designs for Ramadi climate conditions. Two types of absorber plate are fabricated and tested. Type (I) uses an absorber plate without cans, whereas Type (II) uses one with cans, these cans are arranged in a zigzag pattern. These collectors are a single-duct double-pass type. Air first enters through the inlet and then passes over the absorber plate before returning underneath the absorber and moving toward the outlet duct. Moreover, the plate is covered with $4 \mathrm{~mm}$ thick glass. An axial fan is used for air circulation. As a result, the increase in temperature difference is approximately $3^{\circ} \mathrm{C}$ to $10.5^{\circ} \mathrm{C}$ when using aluminum cans with a zigzag array. The increase in thermal efficiency between Types I and II is approximately $20 \%$. Additionally, at an average mass flow rate of $0.075 \mathrm{~kg} / \mathrm{s}$, the difference between the practical and theoretical thermal efficiencies for the two models is approximately $3 \%$.
\end{abstract}

Keywords: SAHs, Solar Dryer, Aluminum Cans, Zigzag, Thermal Performance

\section{Introduction}

Solar radiation is one of the more diverse, abundant and obtainable renewable energy resources. Such energy can be captured and used both directly and indirectly. Moreover, solar power can significantly contribute to reducing carbon emissions from fossil fuels. Solar solutions offer additional opportunities to meet the requirements of planning policies and building regulations [1].

Solar radiation can be directly converted into heat, numerous types of equipment are available to achieve such conversion. A flat plate collector is a device used to achieve this aim. This collector consists of three main parts that govern the design requirements. A glass cover is fixed above the absorber plate, and the system is insulated thermally from the back and sides. Solar air heaters (SAHs) are simple in design and easy to maintain. Corrosion and leakage problems are less severe than those in liquid heater solar systems. Flat plate collectors have been in service for a long time without any significant changes in their design and operational principles [2].

The main drawback of a SAH is that the heat-transfer coefficient between the absorber plate and the air stream is low, which results in low thermal efficiency. If the suggested modifications are implemented, this could improve in the heat-transfer coefficient between the absorber plate and air [3].

Numerous numerical and experimental investigations have been conducted to enhance the thermal performance of flat plate solar collectors. Ion V. ION and Jorge G. MARTINS [4] showed that the performance of air-solar collectors can be enhanced in different ways. These methods include using good thermal insulation, a cover with high transmittance, low absorbance and thermal conductivity of the material as well as using a low-cost absorber with high absorption and thermal conductivity. Also constructing a flow duct with low-pressure losses and using a fan with an appropriate power-flow rate characteristic. Hikmet Esen [5] experimentally analyzed a novel flat plate SAH with several obstacles and another without obstacles. Four types of double-flow solar air collectors under a wide range of operating conditions were studied to evaluate energetic and exergetic efficiencies. Esen showed that the flat plate collector with obstacles had the highest efficiency. Filiz Ozgen et al. [6] experimentally investigated the effect of inserting an absorbing plate made of aluminum cans into the double-pass channel in a flat-plate SAH on thermal performance. Three different absorber plates were designed and tested for the experimental study. They 
found that the optimal collector efficiency was achieved for zigzag cans at a $0.05 \mathrm{~kg} / \mathrm{s}$ mass flow rate. K. Sopian et al. [7] concluded that the addition of porous media to the second channel of the double-pass solar air collector enhanced collector performance. As a result, the typical thermal efficiency of the double-pass solar collector with porous media reached approximately $60-70 \%$. They also found close agreement between the theoretical simulation and experimental data. Ali Zomorodian and Maryam Zamanian [8] experimentally investigated a flat plate solar air collector under direct solar radiation to enhance the thermal efficiency with a slatted glass cover and two different absorber plates with two thicknesses under different air mass flow rates. They found that a maximum thermal efficiency of 0.88 was achieved for the thickest, more porous absorption plate at the highest air mass flow rate.

In this study, a solar air heater with aluminum cans in a zigzag arrangement was constructed to determine the thermal performance of modified SAHs experimentally. The performance was then compared with that of conventional flat plate solar heaters.

The applications of SAHs include the drying or treatment of agricultural goods, space heating, regeneration of dehumidifying agents, seasoning of timber and curing industrial products such as plastics.

\section{Experimental Procedure}

In this experimental work, the performance of conventional absorber plate is compared with the newly proposed absorber plate having aluminum cans.

\subsection{Model I: SAH Collector Without Cans}

Model I, is a solar air collector using an absorber plate without aluminum cans, as shown in Fig. 1(a). Model I has an outdoor flow loop which comprises a conventional absorber plate a single-duct double-pass solar air collector with entrance and exit sections, an air blower, a vane-type anemometer, a pyrometer, and a thermocouple for temperature measurement. A schematic illustration of the SAH collector of Model I is shown in and Fig. 2(a).

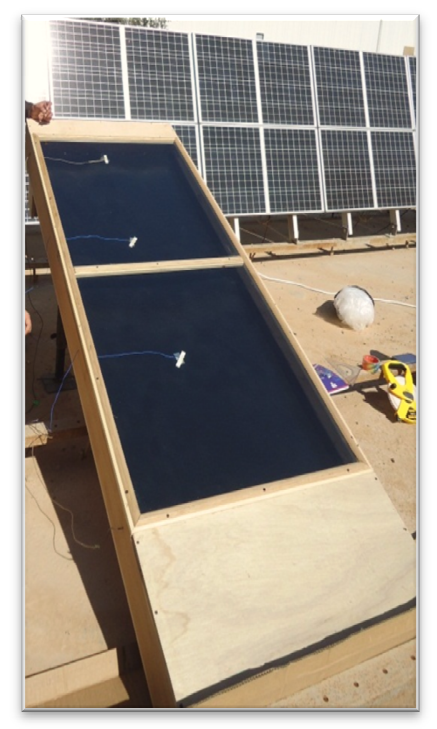

a) Model I

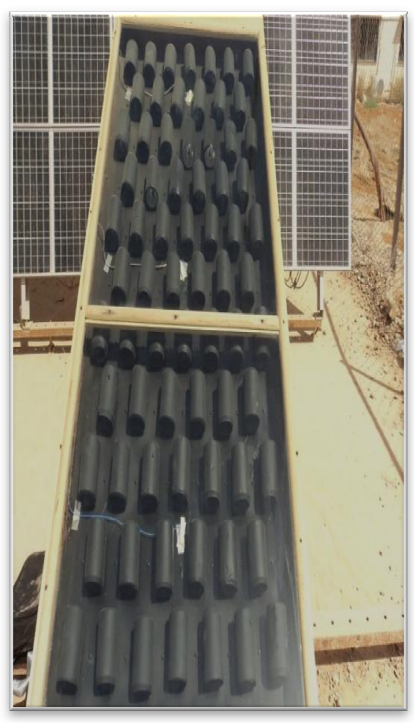

b) Model II
Figure 1. Photographs of SAH collector Models I and II.

\subsection{Model II: SAH Collector with Cans}

Model II, is a solar air collector using an absorber plate with aluminum cans in a zigzag arrangement, as shown in Fig. 1(b). Model II has an outdoor flow loop comprising aluminum cans as obstacles, a single-duct double-pass solar air collector with entrance and exit sections, an air blower, a vane-type anemometer, a pyranometer, and a thermocouple for temperature measurement. A schematic illustration of the SAH collector of Model II is shown in Fig. 2(b).

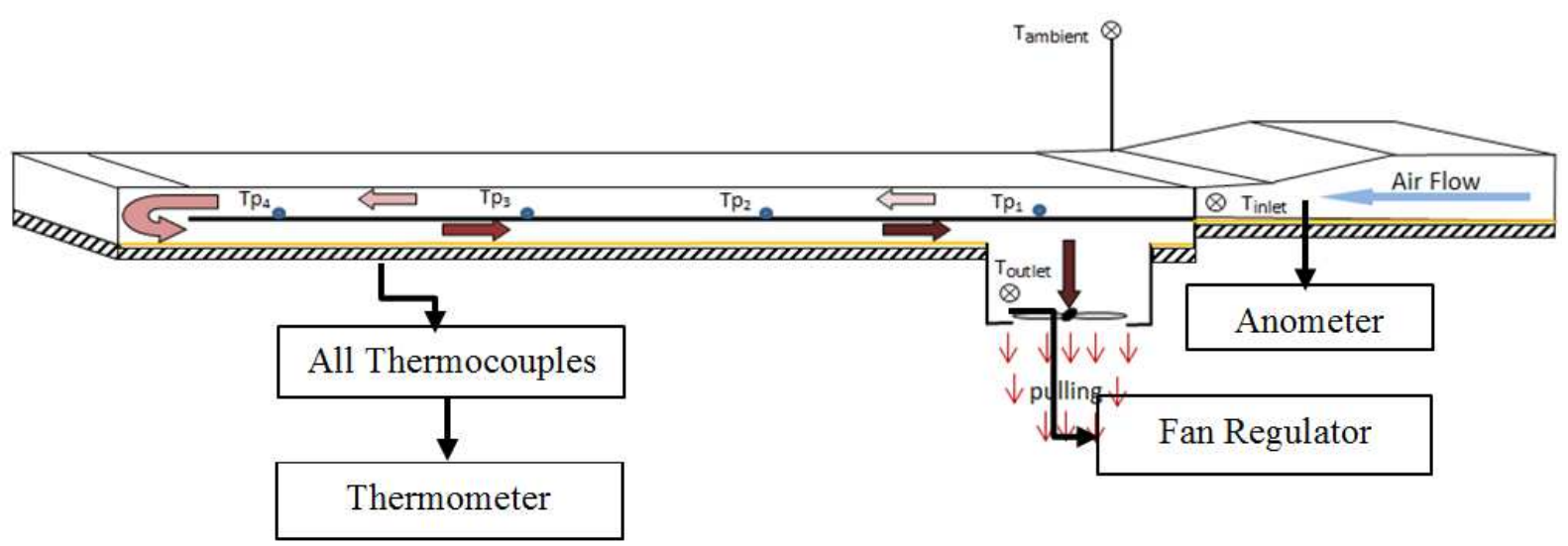

a) Model I (Flat plate collector without Al cans) 


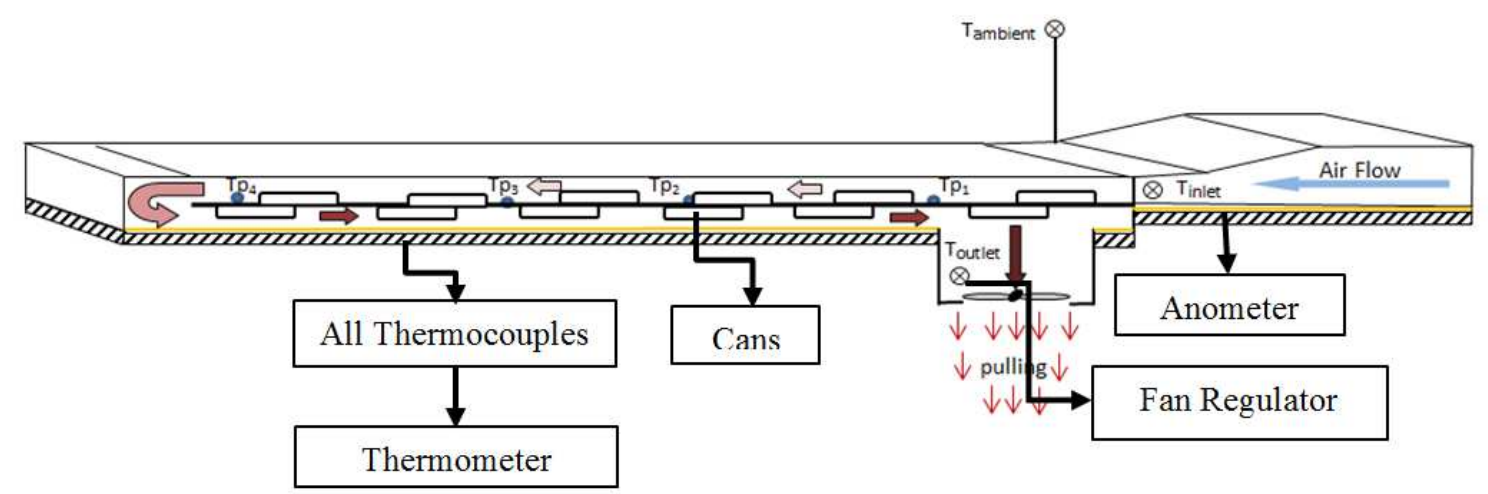

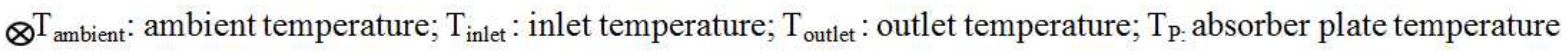

b) Model II (Flat plate collector with Al cans)

Figure 2. Schematic illustration of the SAH collectors: a) Model I and b) Model II.

\subsection{Materials}

The collector plates were $1 \mathrm{~mm}$ thick and made of aluminum sheet with the size $2.20 \mathrm{~m} \times 0.84 \mathrm{~m}$ having a $32^{\circ}$ angle of inclination. The absorber plate was then painted with solar thermal black paint (selective coating). The copper sheet was $0.1 \mathrm{~mm}$ thick and was installed on the bottom duct. The sheet had a specific heat capacity of 0.385 $\mathrm{J} / \mathrm{g} \cdot{ }^{\circ} \mathrm{C}$, thermal conductivity of $386 \mathrm{~W} / \mathrm{m} \cdot \mathrm{K}$, the absorbance of 0.94 , and permeability of 0.03 . The aluminum cans served as obstacles and were placed on the top and bottom of absorber plate. A single glass cover $4 \mathrm{~mm}$ thick was used as glazing for the two collectors. The frame of the collectors was constructed using wood. Therefore, the thermal losses from the back of collectors attributed to conduction, convection, and radiation are assumed negligible. All the specifications of these collectors are shown in Table 1.

Table 1. Specifications of SAH collector.

\begin{tabular}{ll}
\hline Collector tilt angle (degree) & 32 [9] \\
\hline Collector length $(\mathrm{cm})$ & 240 \\
Collector width $(\mathrm{cm})$ & 88 \\
Overall height $(\mathrm{cm})$ & 15 \\
Upper duct height $(\mathrm{cm})$ & 8 \\
Lower duct height $(\mathrm{cm})$ & 7 \\
Inlet Area $\left(\mathrm{m}^{2}\right)$ & 0.0869 \\
Outlet Area $\left(\mathrm{m}^{2}\right)$ & 0.049 \\
Exposed Area $\left(\mathrm{m}^{2}\right)$ & $1.8 * 0.81$ \\
Plate type & Flat plate \\
Cover material & Commercial clear glass $T=0.86[10]$ \\
Number of covers & 1 \\
\hline
\end{tabular}

\subsection{The Measurement}

An auto-controller was used to vary the speed of the air blower. An anemometer was used to measure air velocity. Calibrated copper-constantan thermocouples were used to measure the temperature of the inlet and outlet air. The heated absorber plates were placed in different positions, and temperatures were measured by using a digital thermometer.

All components were checked, and the instruments were calibrated. The axial fan was then switched "on" and joints were checked for leakages. All experiments were conducted under the climatic conditions of Al-Ramadi City (longitude: $33.25^{\circ} \mathrm{N}$; latitude: $43.18^{\circ} \mathrm{E}$; facing south) for two selected clear days on 11 March and 7 April 2014. The average mass flow rate was set at $0.075 \mathrm{~kg} / \mathrm{s}$. The following parameters were measured: solar intensity, absorber plate temperature, inlet air temperature, outlet air temperature and air velocity.

\section{Thermal Performance Calculation}

To calculate the heat gain (qu) and thermal efficiency $\left(\eta_{\text {th }}\right)$ of the solar air collector, the following must be calculated: the average of inlet and outlet temperature $\mathrm{Ti}$ and $\mathrm{To}$, respectively; specific heat capacity of air $\mathrm{Cp}$; density $\rho$; air velocity $v_{\text {inlet}}$, and the inclination of the collector [9]. The thermal gain produced by the SAH can be calculated as in Eq. (1):

$$
\mathrm{q}_{\mathrm{u}}=\dot{\mathrm{m}} \times \mathrm{cp}\left(\mathrm{T}_{\mathrm{o}}-\mathrm{T}_{\mathrm{i}}\right)
$$

Where, $(\dot{m})$ is a mass air flow rate $\left(\mathrm{kg} \mathrm{sec}^{-1}\right)$, which can be calculated as in Eq. (2):

$$
\dot{\mathrm{m}}=\rho \times \mathrm{v}_{\text {inlet }} \times \mathrm{A}_{\text {inlet }}
$$

Where $A_{\text {inlet }}$, is the area of the inlet. The thermal efficiency of the solar air collectors $\left(\eta_{\text {th }}\right)$ is defined as the ratio between the energy gain and the solar radiation incident on the collector plane and can be evaluated as in Eq. (3):

$$
\eta_{\text {th }}=\frac{\mathrm{q}_{\mathrm{u}}}{\mathrm{I}_{\text {tilt }} \times \mathrm{A}_{\text {exposed }}}
$$

where $A_{\text {exposed }}$ is the area covered by the absorber plate $\left(\mathrm{m}^{2}\right)$, and $\mathrm{I}_{\text {tilt }}$ is the intensity of radiation $\left(\mathrm{W} \cdot \mathrm{m}^{-2}\right)$.

\section{Estimation of Solar Radiation}

In this work, the flowchart shown in figure 3 is employed to estimate global solar radiation data by using commonly available meteorological equations through a mutable function, as shown below. Many empirical equations and coefficients have been used to estimate global solar radiation. 
These equations include the location of tests, number of days, latitudinal and atmospheric attenuation coefficients [11, 12]. the inclination of the collector, as well as longitudinal,

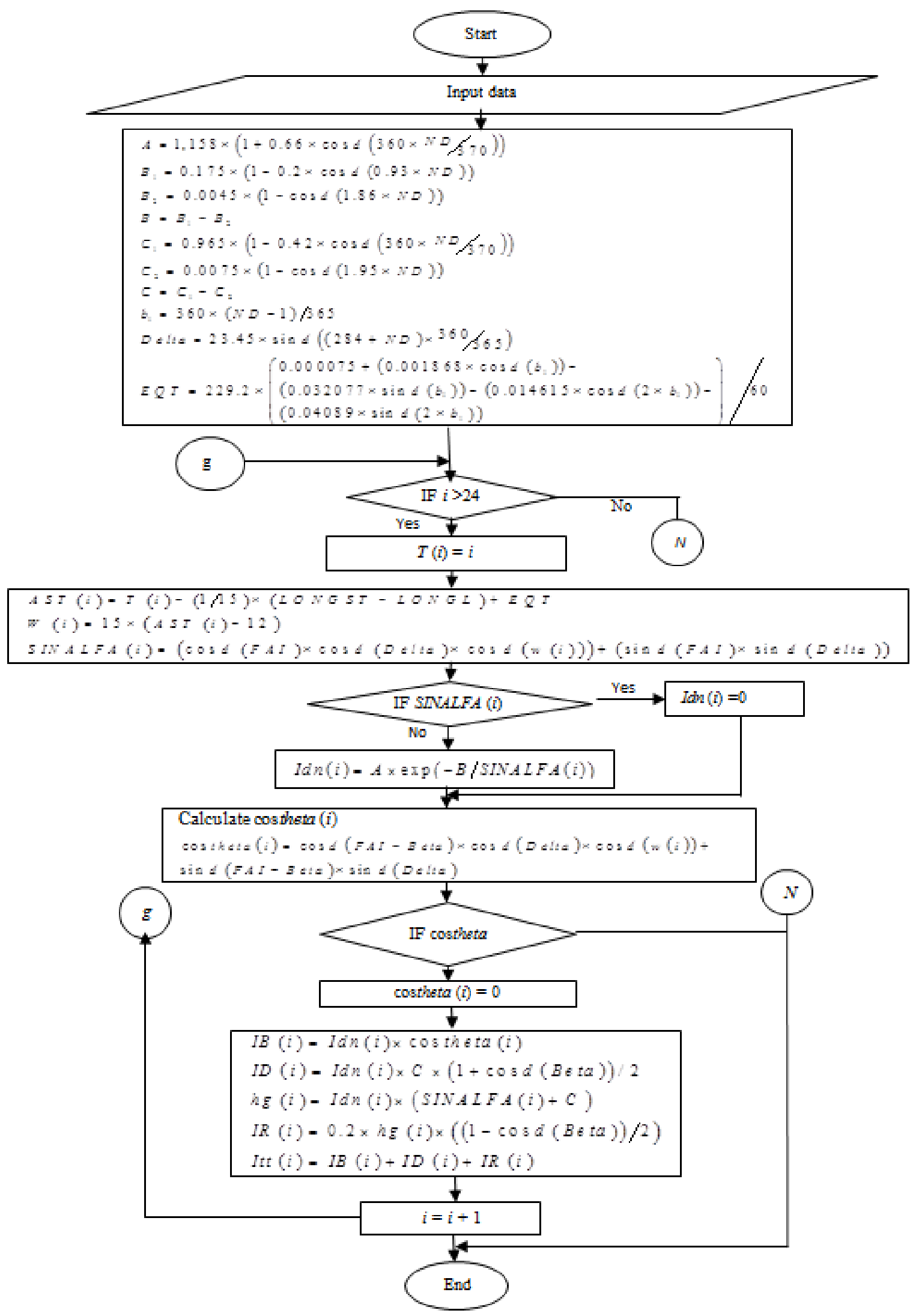

Figure 3. Flowchart used to estimate global solar radiation. 


\section{Results and Discussion}

The practical results acquired in Al-Ramadi City are presented and discussed. All experiments for both collectors were conducted at an average air flow rate of $0.075 \mathrm{~kg} / \mathrm{s}$.

\subsection{Model I: SAH Collector Without Cans}

The values of intensity solar radiation for practical and theoretical conditions which is taken in Al-Ramadi City for the two selected days (11 March and 7 April 2014) are shown in Figs. 4 and 5, respectively. These measurements is also carried out for slope and horizontal plan. The values of incident solar radiation increased gradually to the peak value at midday and then decrease steadily from sunrise to sunset. The practical and theoretical data of the figures $4 \& 5$ have been used to evaluate the hourly and daily variation of a number of parameters such as thermal efficiency. In the other words, these parameters were evaluated based on the experimental data and the estimated values of intensity solar radiation.

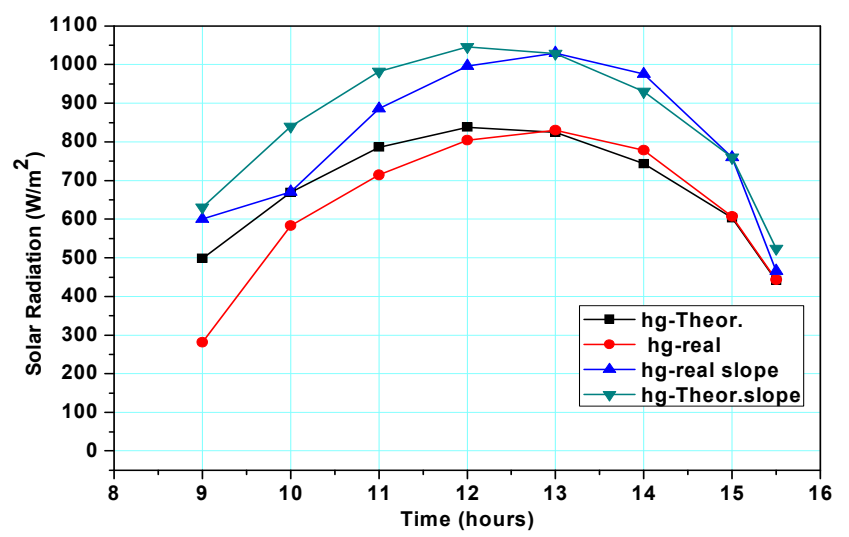

Figure 4. Practical and theoretical values of solar radiation on a clear day on 11 March 2014.

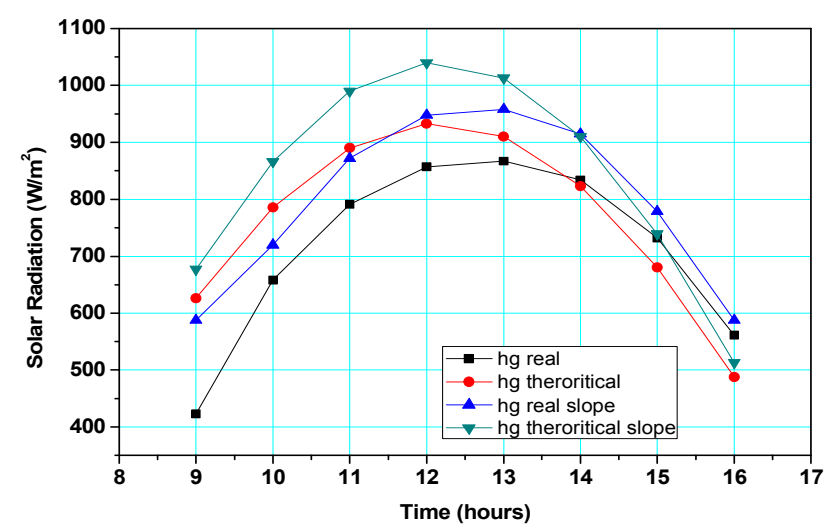

Figure 5. Practical and theoretical values of solar radiation on a clear day on 7 April 2014.

Figure 6 shows the temperature distribution for Model I (without cans) on a clear day on 11 March 2014. For every half hour during daytime; the normal behavior of inlet, outlet, and surface temperatures might be observed for two essential reasons; firstly, the air flow rate fluctuation which could be caused by a number of reasons for instance, the effect of variation of wind speed that could change the air inlet velocity. This variation also affected on wind heat transfer coefficient [10] as shown below:

$$
\mathrm{hw}=5.7+3.8 \mathrm{Vw}
$$

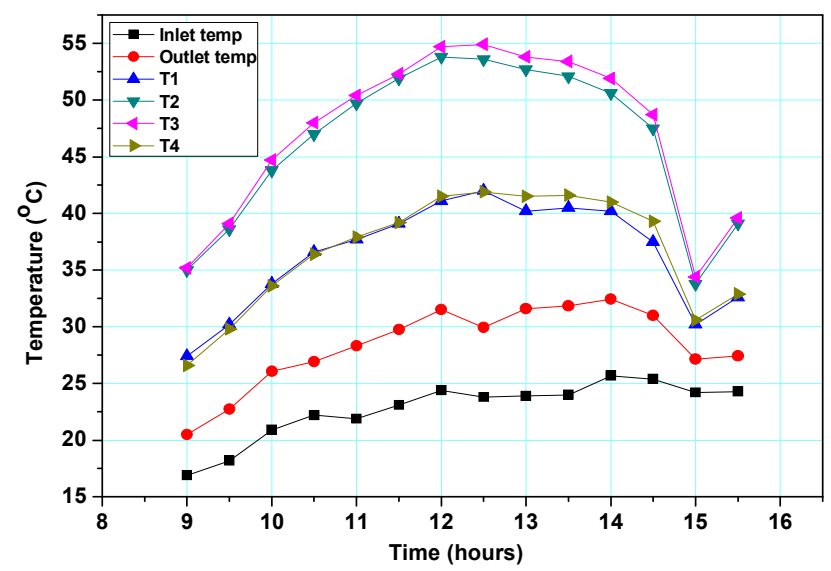

Figure 6. Temperature variation of the inlet, outlet, and surface for Model I on a clear day on 11 March 2014.

The increasing of this coefficient will increase the overall heat transfer losses. In addition, the absence of sun rays for a short time.

The average surface, inlet, and outlet air temperature variations on a clear day on 11 March 2014 are shown in Fig. 7. The maximum difference between inlet and outlet air temperatures was approximately $7^{\circ} \mathrm{C}$ at mid-daytime. Besides, the minimum air temperature difference was about $3.2^{\circ} \mathrm{C}$ at $15: 00$. This attributed for the causes aforementioned above.

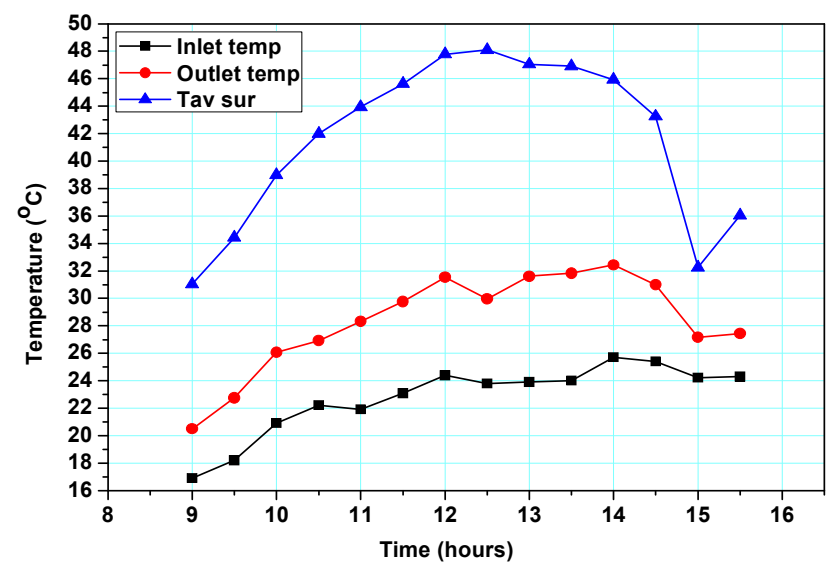

Figure 7. Average surface, inlet, and outlet air temperature variation on a clear day on 11 March 2014.

Fig. 8 shows the hourly practical and theoretical thermal efficiencies for Model I (without cans) on 11 March 2014. The averages of practical and theoretical thermal efficiencies were $49.47 \%$ and $46.5 \%$, respectively. 


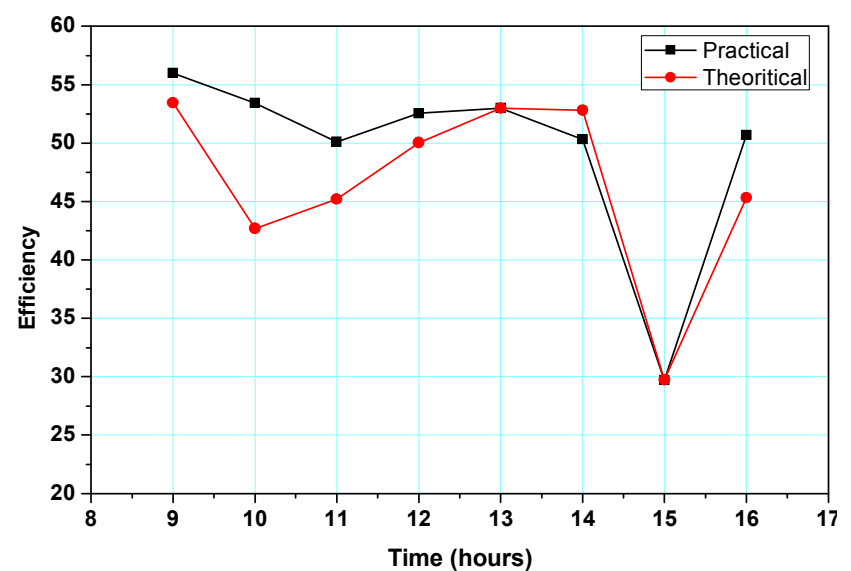

Figure 8. Practical and theoretical thermal efficiencies for Model I on a clear day on 11 March 2014.

\subsection{Model II: SAH Collector with Cans}

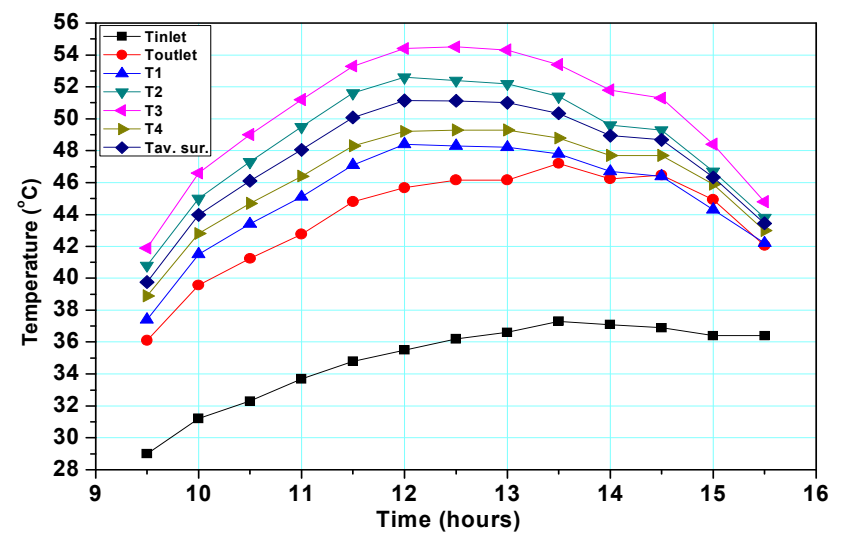

Figure 9. Temperature variation of the inlet, outlet, and surface for Model II on a clear day on 7 April 2014.

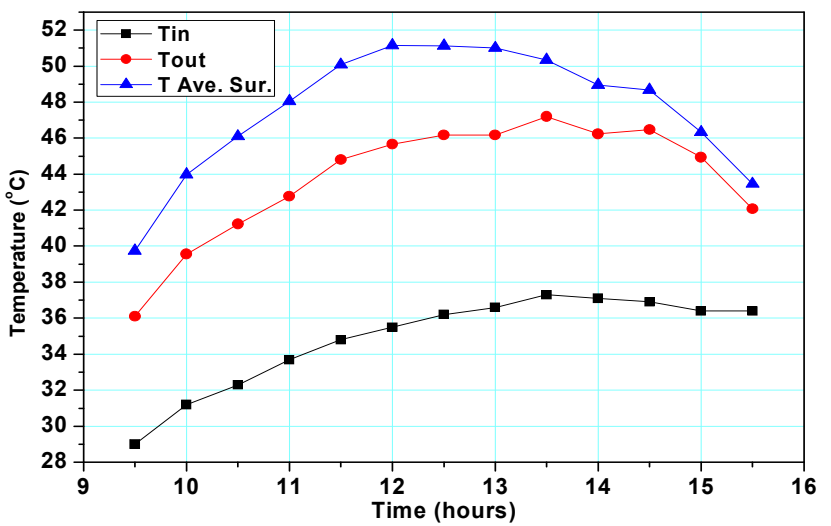

Figure 10. Average surface, inlet, and outlet air temperature variation for Model II on a clear day on 7 April 2014.

Figure 9 shows the temperature distribution for Model II (with cans) on a clear day on 7 April 2014. For every half hour during the daytime, the fairy normal behavior of inlet, outlet, and surface temperatures was observed during the daytime. The average surface, inlet, and outlet air temperature variations on a clear day on 7 April 2014 are shown in figure 10. The maximum difference between inlet and outlet air temperatures was approximately $10{ }^{\circ} \mathrm{C}$ at $13: 30$.
This value is attributed to presence of aluminum cans that act as extended surfaces. Also, the air temperature difference values decreased to less than $2^{\circ} \mathrm{C}$ at $15: 30$ as minimum value owing to the value of intensity solar radiation is quite small which in turn reducing the heat absorbed from aluminum plate.

Fig. 11 shows the hourly practical and theoretical thermal efficiencies for Model II (with cans) on a clear day on 7 April 2014. The averages of practical and theoretical thermal efficiencies were $68.5 \%$ and $65.2 \%$, respectively.

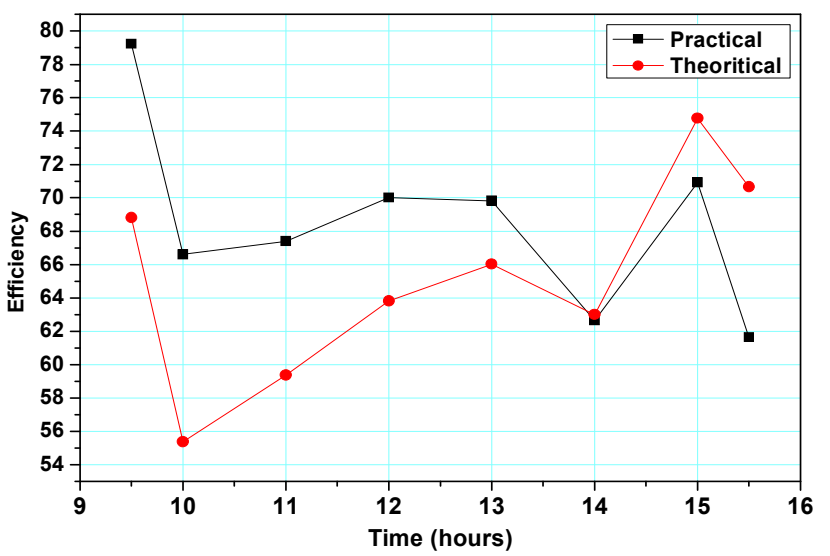

Figure 11. Practical and theoretical thermal efficiencies for Model II on a clear day on 7 April 2014.

\subsection{Comparison Between Model I and Model II}

Figs. 12 and 13 show the increase in the temperature difference between Models I and II for two selected clear days on 11 March and 7 April 2014, respectively. The increase in temperature differences is approximately $3.2^{\circ} \mathrm{C}$ to $10.5^{\circ} \mathrm{C}$. This increase as result of the using aluminum cans with a zigzag array. The aluminum cans serve as fins that increase the capability of the absorber plate to absorb energy, consequently increasing the heat transfer coefficients, as well as contributing to the breakage of the boundary layer and reducing its growth.

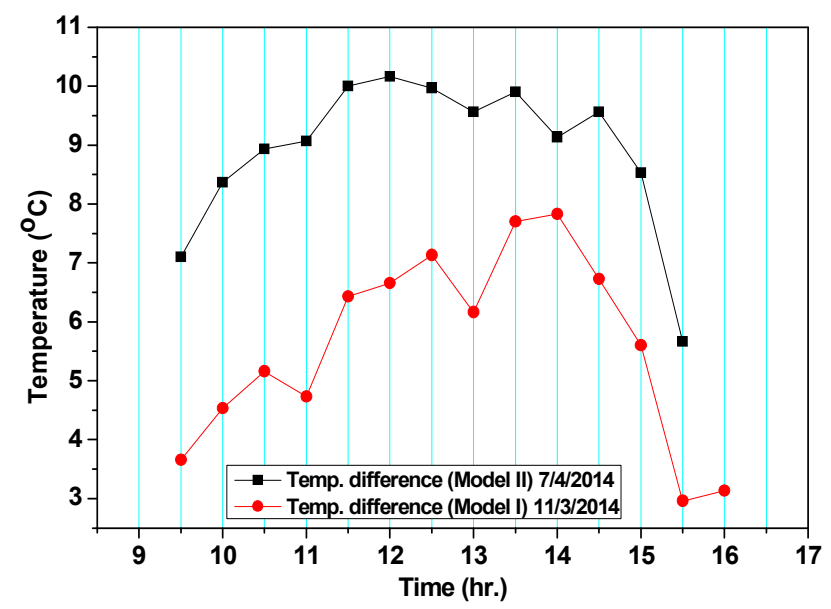

Figure 12. Inlet and outlet temperature difference for Models I and II for the two selected clear days on 11 March and 7 April 2014. 


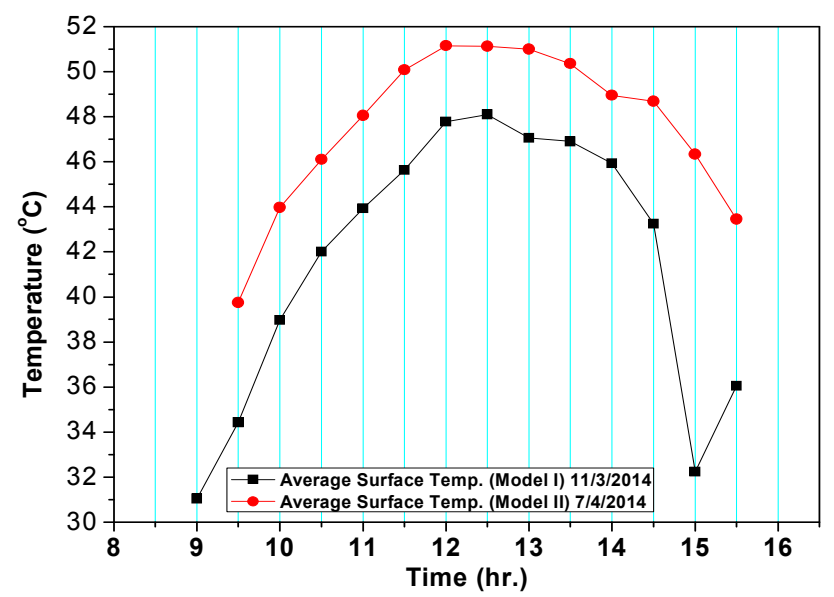

Figure 13. The average surface temperature for Models I and II for two selected clear days on 11 March and 7 April 2014.

Fig. 14 and Table 2 show the experimental and theoretical thermal efficiencies for Models I and Model II for the two selected days. We observe that the difference in the practical and theoretical thermal efficiencies between Models I and II is approximately $20 \%$. In addition, the difference between practical and theoretical thermal efficiencies for the two models is approximately $3 \%$ at an average mass flow rate of
$0.075 \mathrm{~kg} / \mathrm{s}$. The enhanced efficiency of the solar air collector in Model II is attributed to the following reasons: using the cans as extended surfaces (fins) and placing the can array in a zigzag pattern increases the heat transfer coefficient by increasing air turbulent flow and reducing the growth of the boundary layer.

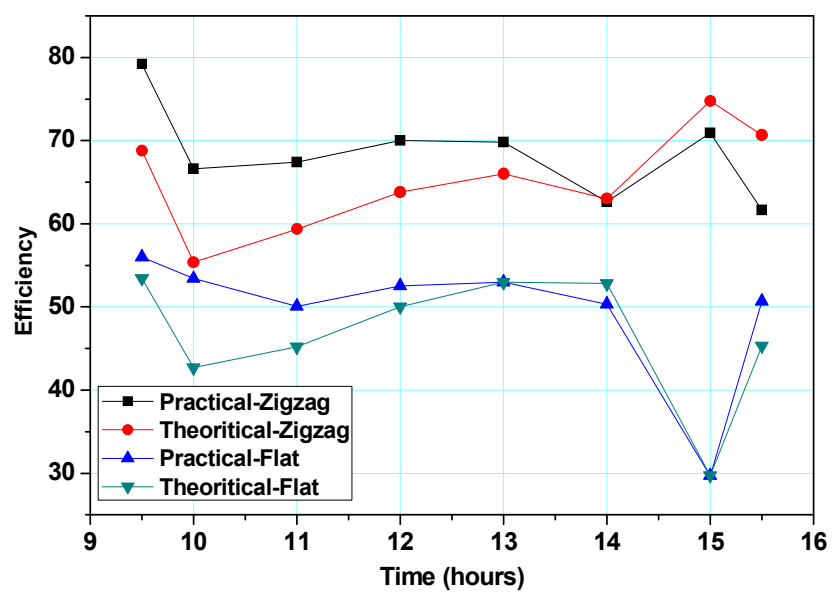

Figure 14. Variation of hourly practical and theoretical thermal efficiencies for Models I and II.

Table 2. Practical and theoretical thermal efficiencies of Models I and II for two selected sunny days on 11 March and 7 April 2014.

\begin{tabular}{lllllll}
\hline \multirow{2}{*}{ Time } & $\boldsymbol{\eta}_{\text {Theoretical }}$ & $\boldsymbol{\eta}_{\text {Practical }}$ & $\mathbf{e}$ & $\boldsymbol{\eta}_{\text {Theoretical }}$ & $\boldsymbol{\eta}_{\text {Practical }}$ & e \\
\cline { 2 - 7 } & Model I & & & Model II & & 7.363810019 \\
\hline $9: 00$ & 53.458 & 56 & 1.797465438 & 68.803 & 79.217 & 7.940809153 \\
$10: 00$ & 42.687 & 53.43 & 7.59644815 & 55.380 & 66.610 & 5.68089588 \\
$11: 00$ & 45.209 & 50.1 & 3.458459267 & 59.375 & 67.409 & 4.378405189 \\
$12: 00$ & 50.042 & 52.55 & 1.773423807 & 63.814 & 70.006 & 2.680641807 \\
$13: 00$ & 52.974 & 53 & 0.018384776 & 66.027 & 69.818 & 0.243244733 \\
$14: 00$ & 52.825 & 50.33 & 1.764231419 & 63.008 & 62.664 & 2.714582933 \\
$15: 00$ & 29.740 & 29.7 & 0.028284271 & 74.763 & 70.924 & 6.375274739 \\
$16: 00$ & 45.321 & 50.7 & 3.803527376 & 70.666 & 61.650 & 2.338932455 \\
Ave. & 46.5 & 49.476 & 2.081899141 & 65.229 & 68.537 & \\
\hline
\end{tabular}

The degree of agreement between the theoretical and experimental results have been calculated by using a statistical analysis [10], as shown below:

$$
\begin{gathered}
\mathrm{e}=\sqrt{\frac{\sum_{i}^{N}=1\left(e_{i}\right)^{2}}{N}} \\
e_{i}=\frac{X_{i}-Y_{i}}{X_{i}} * 100
\end{gathered}
$$

Where $\mathrm{Xi}$ and $\mathrm{Yi}$ are the theoretical and the experimental results of SAH collector, respectively, (e) the root mean square of percentage deviation.

This difference between experimental and theoretical results could be caused by few reasons. One of them, the use practical and theoretical intensity solar radiation values. As it is mentioned before, the percentage error between these solar radiation values around $3 \%$. This percentage affected directly on the calculation of the thermal efficiencies. Another reason, the values of practical intensity solar radiation vary based on the weather conditions such as dust, humidity etc., some values therefore behave convergent at 14:00 and behave divergent at 9:00.

\section{Conclusions}

An experimental investigation was conducted by the Renewable Energy Research Center in Al-Ramadi City to evaluate the thermal performance of two different models of single-pass double-duct SAHs (solar dryers) with and without cans (obstacles) arranged in a zigzag pattern as fins. The thermal performance of the single-pass double-duct type $\mathrm{SAH}$, in which air flows over and returns under the absorber plate, is efficient because the flowing air collects and absorbs most of the supplied energy. The results show an increase in thermal efficiency of Model II by approximately $20 \%$. Model II was more efficient and had a maximum temperature difference that was approximately $10.5^{\circ} \mathrm{C}$ higher than that of Model I. Moreover, the theoretical values of solar radiation used were satisfactory, and the error in the results was approximately $3 \%$. 


\section{Acknowledgements}

This work is supported by the University of Anbar-Iraq/Renewable Energy Research Center with Grant No. RERC-PP34.

\section{References}

[1] Rawlings R and Butcher K. Capturing solar energy. Chartered Institution of Building Services Engineers 2009.

[2] Raj Thundil Karuppa R, Pavan P, and Reddy Rajeev D., "Experimental Investigation of a New Solar Flat Plate Collector", Research Journal of Engineering Sciences, 1(4), pp. $1-8,2012$.

[3] Mohamad AA., "High efficiency solar air heater", Solar Energy, 60(2), pp. 6-71, 1997.

[4] Ion IV and Martins JG., "Design, developing and testing of a solar air collector", Research Journal of Engineering Sciences, 1(4), pp. 1-8, 2012.

[5] Esen H., "Experimental energy and exergy analysis of a double-flow solar air heater having different obstacles on absorber plates", Building and Environment, 43, pp. 1046-1054., 2008.
[6] Ozgen F, Esen M, and Esen H., "Experimental Investigation of Thermal Performance of a Double-flow Solar Air Heater Having Aluminium Cans", Renewable Energy, 34, pp. 2391-2398, 2009.

[7] Sopian K, Alghoul MA, Alfegi EM, Sulaiman MY, and Musa EA., "Evaluation of thermal efficiency of double-pass solar collector with porous-nonporous media", Renewable Energy, 34, pp. 640-645, 2009.

[8] Zomorodian A and Zamanian MA., "Designing and Evaluating an Innovative Solar Air Collector with Transpired Absorber and Cover", International Scholarly Research Network ISRN Renewable Energy; 2012 (Article ID 282538), 5 pages, 2012.

[9] ASHRAE Applications Handbook, American Society of Heating, Solar Energy Use (ASHRAE). Atlanta, GA, 1999, Chapter 32.

[10] Amori KE and Abd-AlRaheem MA., "Field study of various air based photovoltaic/thermal hybrid solar collectors", Renewable Energy, 63, pp. 402-414, 2014.

[11] Duffie JA and Beckman WA., Solar Engineering of Thermal Processes, John Wiley \& Sons, Inc 2006.

[12] Kalogirou S., Solar Energy Engineering: Processes and Systems, Cyprus University of Technology, Elsevier's Science and Technology, USA 2009. 